\title{
WP 34_11
}

\author{
Thanasis Stengos \\ University of Guelph \\ The Rimini Centre for Economic Analysis (RCEA) \\ M. Ege Yazgan \\ Istanbul Bilgi University \\ The Rimini Centre for Economic Analysis (RCEA)
}

\section{Persistence in CONVERGence}

\section{Copyright belongs to the author. Small sections of the text, not exceeding three paragraphs, can be used provided proper acknowledgement is given.}

The Rimini Centre for Economic Analysis (RCEA) was established in March 2007. RCEA is a private, nonprofit organization dedicated to independent research in Applied and Theoretical Economics and related fields. RCEA organizes seminars and workshops, sponsors a general interest journal The Review of Economic Analysis, and organizes a biennial conference: The Rimini Conference in Economics and Finance (RCEF) . The RCEA has a Canadian branch: The Rimini Centre for Economic Analysis in Canada (RCEACanada). Scientific work contributed by the RCEA Scholars is published in the RCEA Working Papers and Professional Report series.

The views expressed in this paper are those of the authors. No responsibility for them should be attributed to the Rimini Centre for Economic Analysis. 


\title{
Persistence in Convergence
}

\author{
Thanasis Stengos \\ M. Ege Yazgan ${ }^{\dagger}$ \\ University of Guelph* Istanbul Bilgi University
}

April 2, 2011

\begin{abstract}
In this paper, we examine the convergence hypothesis using a long memory framework that allows for structural breaks and the non reliance on a benchmark country. We find that even though the long memory framework of analysis is much richer than the simple $I(1) / I(0)$ alternative, a simple absolute divergence and rapid convergence dichotomy produced by the latter is sufficient to capture the behavior of the gaps in per capita GDP levels and growth rates results respectively. This is in contrast to the findings of Dufrénot, Mignon and Naccache (2009) who found strong evidence of long memory for output gaps. The speed of convergence captured by the estimated long memory parameter $d$, is explained by differences in physical and human capital as well as fiscal discipline characteristics of economic policies pursued by different countries.
\end{abstract}

JEL Classification: C32, O47.

Keywords: growth convergence, long memory.

*tstengos@uoguelph.ca

†eyazgan@bilgi.edu.tr 


\section{Introduction}

One of the main predictions of neoclassical growth theory put forward by Solow is that in the long run, all countries with similar technological characteristics could only converge to a single balanced growth path (steady state) equilibrium that will be entirely determined by the exogenously given growth rate of technical progress which will equal labor productivity growth. This is the so called convergence hypothesis, which has been one of the main focal points of the empirical growth literature. On the other hand endogenous growth theories came to offer alternative ways of producing labor productivity growth generated by profit seeking activities endogenously in the economy. These models offered explanations of why certain counties managed to grow faster than others, of how human capital and R\&D accumulation could result in steady growth and of why imperfect competition and international trade permitted productivity gains that could not be reached by closed economies with controlled markets. The growth empirics literature has been one of the most important areas of applied research in the last twenty years and from a methodological point of view different studies incorporate different techniques for testing the convergence hypothesis, using cross sectional, panel data and pure time series methods. Overall, the evidence in favor of convergence has been more present in cross sectional studies, where convergence simply embodies the catching up growth effect where less developed poorer countries approach in equilibrium the (per capita) income levels of richer more developed ones, see Durlauf, Johnson and Temple (2005) for a survey of the recent evidence. In the time series literature, Bernard and Durlauf $(1995,1996)$ have introduced time series interpretations of the convergence hypothesis that can be cast in terms of unit root and cointegration analysis. Pesaran (2007) has extended the time series convergence concepts to the case where there is no requirement that the converging economies to be identical in all aspects including initial endowments. The main result is that for two economies to be convergent it is necessary that their output gap is stationary with a constant mean, irrespective of whether the individual country's output is trend stationary and/or contains unit root. Furthermore, testing for convergence in that case does not rely on using a benchmark country in order to define the output gaps that are used in the analysis and uses a pair-wise approach to test convergence. Pesaran (2007) rejects convergence in output levels and suggests that the evidence in favor of convergence clubs may be spurious. Cheung and GarciaPascual (2004) using panel data methods are more supportive of the convergence hypothesis for the G7 group of countries. 
However, most of the empirical work so far assumes that the empirical analysis of growth convergence can be carried out within a $I(0)$ or $I(1)$ framework, yet it may be that a long memory framework is more appropriate for such an analysis. If per capita output actually follows a fractionally integrated process due to aggregation over heterogeneous units, firms as in Abadir and Talman (2002) or sectors as in Haubrich and Lo (2001 then empirical results based on a simple $I(1) / I(0)$ classification will spuriously find support for or reject convergence. Michelacci and Zaffaroni (2000) introduce fractional integration within a Solow growth model allowing for cross-sectional heterogeneity in how firms adjust their production levels and they find that the standard beta convergence rate is attributable to a long memory parameter lying between 0.5 and 1. More recently, Dufrénot, Mignon and Naccache (2009), henceforth DMN, also use fractional integration analysis to test convergence for a group of developing countries. They introduce an ARFIMA model and they allow for the long-memory parameter $d$ to be greater than 0.5 . In other words, they do not simply restrict $d$ to be in the interval $(-0.5,0.5)$ but they also allow it to be between 0.5 and 1 as well as greater than 1 . This gives rise to a rich classification of convergence cases and DMN are careful to examine the different cases that arise. Their analysis is contrasted with that of transient divergence, see Phillips and Sul (2007a, 2007b), where convergence will take place eventually as divergent dynamics implied by idiosyncratic growth factors will diminish and will be dominated by the common components of economic growth. The main message of $\mathrm{DMN}$ is that for developing countries there is evidence of divergence and growth tragedy where countries do not share common factors and those with initial low income will stay behind others with negative growth rates forever. However, the analysis carried out by DMN is subject to two main caveats. The first is that they use a benchmark to construct output gaps and the second is that they do not consider the issue of structural breaks that will affect the time series properties of the series under consideration. In the case of structural breaks, events that alter the steady state levels of per capita income will also change the mean reversion properties of relative outputs. This is the case of the work of Li and Papell (1999) and Datta (2003) among others. In the standard $I(1) / I(0)$ analysis, when structural breaks are present standard tests of convergence may lack power to reject the null of non-stationarity. The same will be true for an ARFIMA process where the presence of structural breaks may contaminate the dynamics and the classification between different convergence cases depending on the estimates of the long memory parameter $d$. The issue of relying on a benchmark, also renders the analysis problematic as perceived leaders used as benchmark economies may not retain the leader title over the whole period of analysis. In that respect, Pesaran's (2007) pair-wise analysis becomes relevant. 
In this paper, we extend DMN in these two important directions. We examine the effects of structural breaks and the non reliance on a benchmark country on a long memory empirical analysis of the convergence hypothesis. The focus in the paper is, first, the estimation of $d$, that is the parameter that determines the speed of convergence between different economies and second, the examination of the effect on this parameter of certain important characteristics that are embedded in the majority of growth models, such as human capital, macroeconomic stability etc. The main finding of our paper is that even though the long memory framework of analysis that we adopt is much richer than the simple $I(1) / I(0)$ alternative that produces a simple absolute divergence and rapid convergence dichotomy, the latter seems to be sufficient to capture the behavior of the gaps in per capita GDP levels and growth rates results. The former produces a pattern of divergence whereas the latter one of rapid convergence. Any evidence of mean reversion and long memory that we find is not strong enough, contrary to the findings of DMN. The reason for these differences lies in the fact that we do not rely on a benchmark something that introduces a higher degree of persistence in the output gap series. The speed of convergence (divergence) captured by the estimated parameter $d$, is explained by differences in physical and human capital as well as fiscal discipline characteristics of economic policies pursued by different countries. The more dissimilar countries are in terms of these factors the more likely they are to have divergent paths.

The paper is organized as follows. The next section presents the methodology that we follow. We then proceed to present the results first for the output gaps in levels and then growth rates and we also presents some additional results from a subsample of the data that refer to different continents and to developing countries only. The next section presents the analysis from the determinants of the estimated speed of convergence. Finally we conclude.

\section{Testing framework with long memory.}

Following DMN, we will define the pair-wise difference between the log of per capita income of country $i$ and $j$ at time $t$ as

$$
U_{t}=Y_{t}^{i}-Y_{t}^{j}=\beta(t)+Z_{t} \quad Z_{t} \sim I(d), i=1, \ldots, N, i \neq j, t=1, \ldots, T
$$

The process $Z_{t}$ is described as $(1-L)^{d} Z_{t}=\varepsilon_{t}$, where, $L$ is the lag operator and $\varepsilon_{t}$ is the disturbance term. The fractional integration parameter is given by $d$ under the assumption that the process is invertible $(d>-0.5)$. The $\beta(t)$ function is a deterministic function of the time trend 
$t$. For example, DMN assumed that this function is linear $\beta(t)=\beta_{0}+\beta_{1} t$, but following Becker, Enders and Hurn (2004) and Becker, Enders and Lee (2006) and Ludlow and Enders (2000) we let the $\beta(t)$ function be defined in a way that admits structural breaks.

$$
\beta(t)=\beta_{0}+\beta_{1} \sin \left(\frac{2 \pi k t}{T}\right)+\beta_{2} \cos \left(\frac{2 \pi k t}{T}\right)
$$

This functional form allows for the presence of (smooth) structural breaks. Note here that different values of $k$ will have different implications for the permanent or transitory nature of the breaks. If $k$ is an integer then this will result in temporary breaks, whereas fractional frequencies would imply permanent breaks as the function would not complete a full oscillation. One advantage of adopting this specification for structural breaks is that it does not require any prior knowledge on the dates those breaks occur. On the contrary, it assumes that breaks happen smoothly instead of abruptly, something that would make their detection more difficult.

We follow DMN in distinguishing between the different convergence cases that are given from the processes above. Different values of $d, \beta_{0}, \beta_{1}$ and $\beta_{2}$ will define different types of convergence and we enumerate these different convergence cases below. We will only concentrate on the parameter $d$ and we will not pay attention to the $\beta^{\prime} s$, even though the latter are important in the underlying DGP and the classification between unconditional and conditional convergence. For different values of $d$ :

Case 1: $-0.5<d \leq 0$. This is the case of a short memory process, where there is "fast catching-up" or "short memory catching-up".

Case 2: $0<d<0.5$. This is the case of a long memory process, but still stationary process, where there is a slow or smooth decay in the catching-up process. Here, output differences in the remote past will linger on in the current output difference, although with a smaller influence. This is the situation when a country spends a long time on a transition path towards a common long-run trend.

Case 3: $0.5<d<1$. This is the case of a long memory process, which is non-stationary but still mean reverting. In that case the process is characterized by high persistence, whereby any output differences in the distant past will still have a long-lasting influence in the present.

Case 4: $d \geq 1$. This is the case of an explosive process. This is the situation where there is a strong magnification effect and any initial difference is not expected to be reversed in the future. This is the case of "stochastic divergence" and can be compared to the first case of deterministic divergence. 
For completeness, following DMN we also present the distinction between conditional and absolute convergence that depends on the combination of $\beta$-values :

Conditional Convergence (CC): Deterministic Convergence or Conditional Convergence $\left(\beta_{0} \neq 0, \beta_{1}=0, \beta_{2}=0\right)$. Again in this case depending on the value of $d$, we can distinguish three cases:

Case CC.1: $-0.5<d \leq 0$. This is the case of a strict or rapid conditional convergence and has been looked at by Li and Papell (1999).

Case CC.2: $0<d<0.5$. This is the case of a long memory conditional stationary convergence. Here, output differences in the remote past will linger on in the current output difference, although with a smaller influence but convergence will take place.

Case CC.3: $0.5<d<1$. This is the case of a long memory process, which is non-stationary but still mean reverting. In that case output differences in the distant past will have a long-lasting influence in the present, but yet mean reversion and hence convergence will take place.

Conditional Catching Up (CCU): This is the case where $\beta_{0} \neq 0, \beta_{1} \neq 0$ and $\beta_{2} \neq 0$ and the difference vanishes. Depending on the value of $d$ we will have:

Case CCU.1: $-0.5<d \leq 0$. This is the case of a strict or rapid catching up.

Case CCU.2: $0<d<0.5$. This is the case of a long memory conditional stationary catching up.

Case CCU.3: $0.5<d<1$. This is the case of non-stationary long memory catching up.

Absolute Convergence (AC): Absolute or Stochastic Convergence $\left(\beta_{0}=0, \beta_{1}=0, \beta_{2}=0\right)$. In that case depending on the value of $d$ we may have:

Case AC.1: $d=0$. This is the case of zero mean convergence of Bernard and Durlauf (1996).

Case AC.2: $0<d<0.5$. This is the case of a long memory stochastic stationary convergence.

Case AC.3: $0.5<d<1$. This is the case of a long memory mean reverting convergence.

Finally, if $\beta_{0} \neq 0, \beta_{1} \neq 0$ and $\beta_{2} \neq 0$ and $d=0$, but output gaps get bigger and bigger over time if the function $\beta(t)$ is such that it gets bigger and bigger with $t$. This would be the case of conditional divergence when $d=0$.

The above definitions of the different convergence cases allow for a much richer classification of convergence types, whereby one can distinguish between stationary convergence and mean reverting non-stationary convergence and this applies within the conditional as well as the absolute framework. An additional feature of this classification scheme is that it allows for initial differences either to linger on and have a long lasting influence in the present or decay rapidly and play no role 
or be somewhere in-between these two cases. This is something that cannot be captured by the simple $I(0) / I(1)$ classification where there are only two extreme cases, that is perfect persistence or no persistence at all. In our case we will concentrate on the four cases that depend on the values of $d .{ }^{1}$

\section{$2.1 \quad$ Testing for convergence.}

The long memory parameter $d$ is estimated by Whittle estimators that are immune to the presence of nonstationarity. Let $I_{Z}\left(\omega_{j}\right)$ denote the periodogram of a series $Z_{t}$ based on a discrete Fourier transform $W_{Z}\left(\omega_{j}\right)$ at frequency $\omega_{j}=\frac{2 \pi j}{T}$ for $j=0, \ldots T-1$, such that $I_{Z}\left(\omega_{j}\right)=W_{Z}\left(\omega_{j}\right) W_{Z}^{*}\left(\omega_{j}\right)$ with $W_{Z}^{*}\left(\omega_{j}\right)$ being the complex conjugate of $W_{Z}\left(\omega_{j}\right)$ defined as

$$
W_{Z}\left(\omega_{j}\right)=\frac{1}{\sqrt{2 \pi T}}\left|\sum_{t=1}^{T} Z_{t} e^{i t \omega_{j}}\right|^{2}
$$

The discrete Fourier transform $W_{Z}\left(\omega_{j}\right)$ can be used to define a Whittle estimator of $d$ obtained by minimizing the objective function below with respect to $d$ :

$$
W H(G, d)=\frac{1}{v} \sum_{j=1}^{v}\left(\ln \left(G \omega_{j}^{-2 d}\right)+\frac{I_{Z}\left(\omega_{j}\right) \omega_{j}^{2 d}}{G}\right), G \in(0, \infty)
$$

where $v$ is the number of frequencies used in the estimation. The most well known Whittle estimator that is valid under nonstationarity is Exact Local Whittle (ELW) estimator of Shimotsu and Phillips $(2005,2006)$. This estimator is consistent and has the same $N\left(0, \frac{1}{4}\right)$ limit values for all values of $d$. The word "exact" is used to distinguish this estimator, which relies on exact algebraic manipulation, from the conventional Local Whittle of Kuensch (1987) and Robinson (1995) (LW), which is based on an approximation of Whittle likelihood function and is not a good general-purpose estimator when the value of $d$ may take on values in the non-stationary zone beyond $\frac{3}{4} . .^{2}$

However, the ELW estimator has also been shown to have some undesirable properties. As shown by Shimotsu (2008), if an unknown mean (initial value) is replaced by its sample average,

\footnotetext{
${ }^{1}$ The reason for that will become apparent from the results that we present below, which overwhelmingly point towards lack of convergence in output levels. In that case, the distinction between conditional and unconditional types of convergence becomes superfluous.

${ }^{2}$ Although these estimators are consistent for $d \in\left(\frac{1}{2}, 1\right)$ asymptotically normally distributed for $d \in\left(\frac{1}{2}, \frac{3}{4}\right)$, they are also known to exhibit nonstandard behavior when $d>\frac{3}{4}$. For instance, they have a non-normal limit distribution for $d \in\left(\frac{3}{4}, 1\right)$, and they converge to unity in probability and are inconsistent for $d>1$ (see Shimotsu and Phillips 2005,2006)
} 
simulations suggest that the ELW estimator is inconsistent for $d>1$. Furthermore, if an unknown mean is replaced by the first observation, the consistency and normality of ELW estimator for $d \in\left(0, \frac{1}{2}\right)$ requires a strong assumption on the number of ordinates used in estimation, and simulations suggest that the estimator is inconsistent for $d \leq 0$. Hence, an unknown mean needs to be estimated carefully in the ELW estimation. Shimotsu (2008) modifies the ELW objective function to estimate the mean by combining two estimators: the sample average and the first observation and denotes the resulting estimator as 2 Stage Feasible Exact Local Whittle (2FELW). The 2FELW estimator, which uses the tapered estimator of Velasco (1999) in the first stage, has the same $N\left(0, \frac{1}{4}\right)$ limit distribution for $d \in\left(-\frac{1}{2}, 2\right)$ and is consistent when $d>\frac{1}{2}$. Moreover, the finite sample performance of the 2 FELW estimator inherits the desirable properties of the ELW estimator. This estimator can be also computed with prior detrending (2FELWd) of the data, see Shimotsu (2008). Finally we also apply the fully extended local Whittle estimator (FELW) of Abadir et al. (2007), which uses a fully extended discrete Fourier transform. The FELW estimator is shown to be consistent and has a $N\left(0, \frac{1}{4}\right)$ distribution for $d \in\left(-\frac{3}{2}, \infty\right)$. As in the case of $2 \mathrm{FELWd}$, the FELW estimator is also computed with prior detrending (FELWd). The 2FELW and FELW estimators can be regarded as being complementary to each other for a variety of reasons. The FELW estimator has the advantage over the 2FELW estimator in that it covers a wider range of $d$, and it does not require estimating the mean. However, the FELW estimator excludes the values of $d=\frac{1}{2}, \frac{3}{2}, \ldots$, which results in "holes" in the confidence intervals at these points, whereas the two-step approach does not (see Shimotsu, 2008, for a comprehensive comparison and discussion of the two estimators). ${ }^{3}$

All LW, ELW FELW, FELWd, 2FELW, 2FELWd estimators are used to estimate $d$ and $v$ is chosen as $v=T^{0.6}$ as suggested by Shimotsu (2008). Then, following DMN, we perform the following tests:

Test 1: $H_{0}^{0}: d=0$ against $H_{1}^{0}: d>0$ (short memory against long memory)

Test 2a: $H_{0}^{1 / 2 a}: d=0.5$ against $H_{1}^{1 / 2 a}: d<0.5$ ("limit" stationary long memory against stationary convergence)

Test 2b: $H_{0}^{1 / 2 b}: d=0.5$ against $H_{1}^{1 / 2 b}: d>0.5$ ("limit" stationary long memory against non-stationary convergence or mean reverting process)

Test 3: $H_{0}^{1}: d=1$ against $H_{1}^{1}: d<1$ (unit root against a mean reverting process)

Test 4: $H_{0}^{1}: d=1$ against $H_{1}^{1 \exp l}: d>1$ (unit root against stochastic divergence)

\footnotetext{
${ }^{3}$ Hence, FEWL estimators cannot be used under the null hypothesis of test 3 below. Nevertheless we still used them for this case also for completeness as they yielded similar results to the others.
} 


\subsubsection{Monte Carlo based critical values.}

We conduct Monte Carlo simulations to compute the critical values of the statistic corresponding to each of the above tests under the null hypothesis under consideration. The test statistic is computed as

$$
\frac{\sqrt{v}\left(\widehat{d}-d_{0}\right)}{\sigma(\widehat{d})}
$$

where, $d_{0}$ is the value of $d$ under the null hypothesis, $\widehat{d}$ is the estimate of $d$ and $\sigma(\widehat{d})$ its asymptotic standard error. For the simulations of the critical values, we consider 50000 iterations. For each iteration we generate a series from $Z_{t}=U_{t} \sim I(d)$ for different values of $d$ corresponding to the different null hypotheses listed above. Note that in this case we do not rely on a specific $\beta(t)$-function with particular parametric values of the $\beta$-parameters to obtain the critical values of the various test statistics. The latter will be obtained on the assumption that we are looking at "de-trended" data.

Under asymptotic theory provided in Shimotsu (2008) among others, all the Whittle estimators considered here, except LW, which exhibits nonstandard behavior when $d>3 / 4$, are distributed as $N\left(0, \frac{1}{4}\right)$ under all of the null hypotheses defined above. Hence the above test statistic is expected to be distributed as standard normal under each null. Therefore the purpose of the present Monte Carlo analysis is to control for small sample deviations from the asymptotic distribution. In Table A1 of the Appendix we provide critical values at 5 and 10 percent significance levels for $T=100,200,500^{4}$. These critical values are then used in the empirical analysis that follows.

\section{Empirical Findings.}

The data consist of annual GDP data for the period 1945-2006 and for 139 countries. ${ }^{5}$ The data come from Madison $(2008)^{6}$ and they include all possible countries available, not just the group of developing countries considered by DMN. $(T=62 ; N=139)$. The four tests outlined above are applied to all possible pairs of $U_{t}=Y_{t}^{i}-Y_{t}^{j}, i=1,2, \ldots, N-1$, and $j=1,2, \ldots, N$. We first investigate the convergence of GDP per capita and GDP data for all the 139 countries taken

\footnotetext{
${ }^{4}$ It becomes clear from the table that the quantiles of the reported distributions converge to those of the standard normal as $T$ increases, but slowly and show significant differences across estimators. The graphics and some summary statistics of these distributiona are available upon request.

${ }^{5}$ The list of the countries listed in different groups can be found in Table A2 of the Appendix.

${ }^{6}$ Some countries have some missing observations at the beginning of the period. The latest starting date in our sample is 1950. The data source is www.ggdc.net/maddison/.
} 
together as a group and then separately as belonging to different continents (Middle East and Central Asia, Europe, Asia and Pacific, Sub-Saharan Africa, Western Hemisphere). ${ }^{7}$

As in Pesaran (2007), we analyze output convergence across 139 countries without being subject to the pitfalls that surround the use of a benchmark to construct the output differences. As such we examine all $N(N-1) / 2=9591$ output gaps. Under the null hypothesis of each test, we would expect the fraction of output gap pairs for which the null hypothesis is rejected to be close to the size of the test applied to the individual output gap pairs. Hence, in the tables rejection frequencies that greatly exceed a nominal size of, say 0.05 would be taken as evidence against the null. Conversely, rejection frequencies that are less than the nominal size value will be taken as evidence in favor of the null. ${ }^{8}$ Furthermore, following DMN, we will analyze the nature of convergence depending on the classification presented in Table 1 below.

Table 1: Type and Nature of Convergence according to the Estimate of $d$

\begin{tabular}{|c|c|c|c|}
\hline & \multicolumn{2}{|c|}{$H_{0}^{0}$ rejected $(d>0)$} & $H_{0}^{0}$ not rejected $(d=0)$ \\
\hline & $\begin{array}{c}H_{0}^{1 / 2 a} \text { rejected } \\
(d<0.5)\end{array}$ & $\begin{array}{c}H_{0}^{1 / 2 b} \text { not rejected } \\
(d \geq 0.5)\end{array}$ & \\
\hline$H_{0}^{1}$ is rejected $(d<1)$ & $\begin{array}{c}\text { Stationary } \\
\text { convergence }\end{array}$ & $\begin{array}{c}\text { Mean-reverting } \\
\text { convergence }\end{array}$ & Rapid convergence \\
\hline $\begin{array}{c}H_{0}^{1} \text { is not rejected against } H_{1}^{1}(d=1) \\
\text { or rejected against } H_{1}^{1 \exp l}(d>1)\end{array}$ & \multicolumn{2}{|c|}{ Absolute divergence } & Indeterminate outcome \\
\hline
\end{tabular}

\subsubsection{Detrending for structural breaks}

To control for structural breaks we detrend the data by estimating the $\beta_{0}, \beta_{1}, \beta_{2} s$ in equation (1) for 30 different values of $k=0.1,0.2, \ldots ., 2.9,3.0$ and by subtracting the estimated $\beta(t)$ function from the data series $U_{t}$, before estimating the $d^{\prime} s$ and performing the different tests. In the simulations where we obtained the critical values for the various test statistics we assumed that the data had already been detrended. Detrending for structural breaks after estimating the $\beta(t)$-function avoids the problem of having to rely on specific values of the $\beta$-parameters to obtain critical values in the simulations. Hence the test results will avoid possible misspecification due to the

\footnotetext{
${ }^{7}$ This classification is based on the usual classification made by the International Monetary Fund's regional economic outlook documents.

${ }^{8}$ Although the underlying individual tests are not cross-sectionally independent, under the null, the fraction of rejections is expected to converge to $\alpha$, as $N$ and $T \rightarrow \infty$, where $\alpha$ is the size of the underlying test.
} 
reliance on "incorrect" $\beta$ parameter values.

\subsection{Pair-Wise Results for Per Capita Output Gaps.}

The first horizontal panel (denoted by ALL) of Table 2 summarizes the results of the five tests applied to all 9591 output gap pairs over the period 1945-2006 $(T=62 ; N=139)$ for the level GDP per capita data at the 5 percent significance level based on critical values computed for $T=100$ and Table 3 for $T=200^{9}$. The tables show the rejection frequencies of the five tests defined above. We report the minimum (Min), median (Med) and maximum (Max) of these rejection frequencies obtained from the 30 different detrended series as explained above.

Table 2

Table 3

As can be seen from the above tables all the maximum, median and even minimum of rejection frequencies of test $2 \mathrm{a}$ are well below the significance level (0.05) for all the of the estimators of the $d$ parameter and for critical values using both $T=100$ and $T=200$ estimators. Similarly the evidence from tests $2 \mathrm{~b}, 3$ and suggests that $d$ is greater than its limit value 0.5 and possibly unity or greater than unity, in short $d>0.5$. The above results point to the low power of the tests used. However, even though we cannot distinguish between a long memory non stationary mean reverting and a non stationary unit root or even explosive process, the evidence strongly rejects stationarity. Overall, even though we cannot entirely exclude the possibility of mean reversion, the evidence points strongly towards a non-mean reverting process for the per capita output gaps. As a result, we may conclude that output gaps for GDP per capita for the all country group are consistent with any variety of non stationary behavior, long memory, unit root or even explosive ${ }^{10}$. We repeat the analysis for different group of countries, the Middle East and Central Asia, Europe, Asia and the Pacific, Sub-Saharan Africa, and the Western Hemisphere. The results

\footnotetext{
${ }^{9}$ To conserve space we only report the results of the FELW, FELWd, 2FELW and the 2FELWd estimators as the other two estimators give very similar results. We also do not report the results for the 10 percent significance level for the same reason. These results are available upon request.

As mentioned above FELWd and 2FELWd apply (linear) prior detrending the data. Therefore we also control for linear trends that may be present in the data via these estimators.

${ }^{10}$ The results for the GDP output gap series are similar to the GDP per capita gap series and are not reported. They are available upon request.
} 
are reported in the lower horizontal panels of Tables 2 and 3. The classification of countries falling into one of the above regions is given in Table A2 of the Appendix. Except for Europe and the Western Hemisphere countries, where the results indicate a long memory process with possibly mean reverting behavior and little or no evidence of divergence, the results for all the other regions are qualitatively similar to those obtained for the group of countries taken as a whole. They point out a for a (long memory) unit root process for per capita output gap series and strong evidence for divergence.

We use the classification of Table 1 above to examine the nature of convergence that was established in Tables 2 and 3. We compute the rejection frequencies of the cases consistent with the stationary, mean-reverting, rapid convergence and absolute divergence and indeterminacy hypotheses based on the estimate of the long memory parameter $d$ over all 9591 output gaps for GDP per capita. As before we compute these fractions for the 30 different "detrended" series and report only minimum, median and maximum values. The results strongly support rejection of all forms of convergence considered. We only report the case of absolute divergence in the last vertical panel of Tables 2 and 3 as this is the only one where the evidence is supportive of the null. The evidence here is consistent with the test results for $d$ as it points towards is a non-mean reverting diverging process for the per capita output gaps. Note that the distinction between absolute and conditional convergence is of importance only if one operates in a "convergence" regime and it is not relevant if there is lack of convergence. Hence, since the the test statistics that we obtain based on the estimated $d$-values suggest lack of convergence, the conditional/absolute distinction becomes irrelevant.

Overall, with the possible exception for European and Western Hemisphere countries, the evidence in favor of divergence is quite striking. Given these results there is no scope in further investigating the distinction between absolute and conditional convergence based on the estimated $\beta$-values. The results that we find are partly in agreement with DMN who also found strong evidence of long memory and absolute divergence. However, we find more support for a divergence than they do. One of the main reasons for the differences between our results and theirs is that using pair wise comparisons for all possible pairs within a group as opposed to relying on a benchmark, produces greater gap differences that lead to divergence. These differences are smoothened out if gaps are only constructed as a difference of individual countries from the leader in the group. Interestingly enough, even though the evidence does not rule out the possibility of long memory behavior in the transitional dynamics of the output gaps, it is the absolute divergence behavior that seems to be the dominant pattern. 
The main premise of the convergence hypothesis is based on the "catching up growth" effect, where less developed poorer countries approach in equilibrium the (per capita) income levels of richer more developed ones by growing faster than them. In that case, a "large" initial output gap in GDP per capita levels between two countries can be reversed if only there is a "reverse" gap in growth rates between these two counties. In other words, divergence in the gaps of growth rates is consistent with convergence in the per capita output gaps in levels. Having found strong evidence of absolute divergence in the level output gaps it is interesting to see the pattern of convergence in the growth gaps and see how it differs from that in levels.

\subsection{Pair-Wise Results for Gaps of Per Capita Growth Rates.}

In this section we repeat the above analysis by using gaps of output growth instead of output level. Table 4 below summarizes the results of the tests applied to all 9591 GDP per capita growth gap pairs over the period 1946-2006 $(T=61 ; N=139)$ at the 5 percent significance level for $\mathrm{T}=100$ and Table 5 for $\mathrm{T}=200$.

Table 4

Table 5

For the whole group of countries, as can be seen from Tables 4 and 5, rejection frequencies of test 3 are all well above the significance level. Hence, the evidence points strongly towards a mean reverting process for the output growth gaps. All of the rejection frequencies for test $2 \mathrm{~b}$, are below the 0.05 level, providing evidence against stochastic divergence, non stationary long memory but in favor of "limit" stationary long memory. The evidence of test 1 suggests that the process may not be difference stationary, although the rejection frequencies are not far from the 0.10 level. As a result, we may conclude that for the group of countries taken as a whole, output growth gaps for GDP per capita point towards $d$ being in the range $0 \leq d<0.5$. As a result the evidence is somehow mixed and weak (if any) on long memory, but strong on limit stationarity with mean reverting behavior. Compared to the GDP per capita case, where the evidence on long memory (with unit root) was quite clear, the evidence here points towards mean reverting behavior rather than unit root. For the levels we found strong evidence that $d>0.5$, whereas for the growth rates $d<0.5$. 
We also examined the nature of convergence as we did in the case of the per capita output gaps. We found, unlike the GDP per capita case, that the only type that cannot be ruled out is rapid convergence. The results are reported in the last vertical panel of Tables 4 and 5 . The rest of convergence types (stationary and mean reverting) are decisively rejected and so is absolute divergence unlike the GDP per capita levels. ${ }^{11}$ Hence, the process that characterized best the output gap GDP per capita growth series is a short memory process with evidence for rapid convergence.

The analysis is repeated it for the other regions, the Middle East and Central Asia, Europe, Asia and the Pacific, Sub-Saharan Africa, and the Western Hemisphere and the results are presented in the lower horizontal panels of Tables 4 and 5. The results are qualitatively similar to those obtained for the whole group of countries, with some exceptions. For Middle East and Sub-Saharan Africa the case for rapid convergence is weaker, while for Europe and the Western Hemisphere, the evidence for rapid convergence is strongest as expected.

Overall, however, gaps in growth per capita rates point towards a rapid convergence pattern characterized by short memory. Interestingly, even though the framework of analysis that the we have pursued provides a richer set of possibilities than the rapid convergence and absolute divergence dichotomy, it is the latter these two possibilities that have emerged as the dominant hypotheses from the results that we have obtained. In other words, it seems that the $I(0) / I(1)$ dichotomy is what drives the results here and other values of $d$, even though they cannot be ruled out due to low power considerations, they do not seem to be important. The latter has emerged as the dominant characterization of output gaps in per capita GDP levels and the former for the gaps in per capita growth rates. The results produce a picture where the diverging GDP levels are not reversed by higher and reverse growth rates. In fact it seems, that growth rates do not make up for the differences in initial GDP levels and if anything the latter keep diverging between countries. The main premise of the convergence hypothesis that countries with lower initial endowments will grow faster to "catch-up" with richer economies is not borne out by the evidence here.

\footnotetext{
${ }^{11}$ The results are not reported but are available on request.
} 


\subsection{Developing World.}

To make our work more comparable to DMN, which consider only the developing world, we now repeat the above analysis by excluding developed countries from our sample. By doing so we recalculate rejection frequencies for 118 developing countries ${ }^{12}$ for levels and growth rates. The results are presented in the last horizontal panels of Tables 2-5.

The results are very clear in giving strong support to the dichotomy between absolute divergence and rapid convergence. Overall, the convergence patterns in the developing world is best characterized by absolute divergence in output gaps and (weak) rapid convergence in growth rates.

\subsection{Pesaran's Measures of Pair-Wise Convergence.}

In the above cases (levels and growth rates) we also look at the Pesaran's (2007) measures of pair-wise convergence, see also Mello (2010) who used the applied these measures to check for stochastic convergence of income among US states.

$$
D_{t}^{2}=\frac{2}{N(N-1)} \sum_{i=1}^{N-1} \sum_{j=i+1}^{N}\left(y_{i t}-y_{j t}\right)^{2}
$$

and

$$
M D_{t}=\frac{2}{N(N-1)} \sum_{i=1}^{N-1} \sum_{j=i+1}^{N}\left|y_{i t}-y_{j t}\right|
$$

The first measure captures the notion of $\sigma$-convergence and the second one is related to the Gini coefficient. Both of these measures use all pairs of income and plotting them allows for a quick view of the presence of convergence patterns consistent with $\sigma$-convergence. Figures 1 and 2 present the graphs of $D^{2}$ and $M D$ for the per capita GDP and per capita GDP growth differences respectively. It is clear from the graphs that for all GDP per capita series, except for the group of European countries, there is strong evidence of divergence, whereas there is strong evidence of convergence for the per capita GDP growth series. These findings are consistent with

\footnotetext{
${ }^{12}$ These countries are obtained by excluding the following 21 countries from 139 countries listed in Table A3 of the Appendix: Australia, Austria, Belgium, Canada, Denmark, Finland, France, Germany, Greece, Italy, Ireland, Japan, Netherlands, New Zealand, Norway, Portugal, Spain, Sweden, Switzerland, United Kingdom, United States. Note also that DMN include 98 of these 118 developing countries into their data set.
} 
the results of absolute divergence that we have found for the per capita series and those of rapid convergence for the growth series.

\section{Determinants of persistence.}

The above analysis strongly points to the presence of high persistence and divergences, in the output level gap pairs. However in growth rates the process seems to follow a mean reverting rapid converging path. In this section we analyze the determinants of these different paths of output gaps in levels and growth rates by running the following regression

$\hat{d}_{i j}=\gamma_{1} B U D_{i j}+\gamma_{2} I N V_{i j}+\gamma_{3} I N F_{i j}+\gamma_{4} I N Y_{i j}+\gamma_{5} P O P_{i j}+\gamma_{6} H C_{i j}+u_{i j}, i=1, \ldots, N, i \neq j$

The $\hat{d}_{i j}^{\prime} s$ refer to the estimated $d$ for the $i j$ pairs obtained in the previous analysis. $B U D_{i j}$ is the absolute difference between the budget deficit as a percentage of GDP for the $i j$ country pairs. Similarly, $I N V_{i j}, I N F_{i j}, I N Y_{i j}, P O P_{i j}, H C_{i j}$ refer to the (absolute) differences between the investment as a percentage of GDP, inflation rates, initial GDPs, population growth, and human capital respectively. $u_{i j}$ represents the error term that could be cross sectionally correlated and possibly heteroskedastic ${ }^{13}$. The data set for the explanatory variables is, unfortunately, available only for a subset of countries without interruption for a given period. We use two different sets belonging to two different time periods. In the larger data set, we have the time averages of those variables for 62 countries over the period of 1970-2001, hence we have 1891 country pairs and as such 1891 observations to run the above regression. In the smaller data, which covers the period of 1960-2001, there are 33 countries, hence we have only 528 pairs. The list of these countries can be found in Table A3 in the Appendix. Since a measure of the speed of convergence/divergence is given by the estimated $d^{\prime} s$, this regression aims to assess the role of the factors determining this speed. A higher value of $d$, represents a less convergent (and possibly divergent) output gap. Hence, we expect that the larger the difference between these factors for the $i j$ country pair, the larger the value of the $\hat{d}_{i j}$ for that pair. As such we expect the signs of $\gamma^{\prime} s$ to be positive.

\footnotetext{
${ }^{13}$ The data sources are the following: Barro and Lee (2001), Vikram and Dahreshwar (1993), Vikram, Swanson and Dubey (1995), WDI World Development Indicators on CD-ROM, The World Bank. 2009, WDI World Development Indicators on CD-ROM, The World Bank, 2010.
} 
We run this regression for the two sets of $d^{\prime} s$, estimated from both level and growth rates data. Table 6 summarizes the results of OLS estimation for the above regression ${ }^{14}$

Table 6: Regression results

\begin{tabular}{|c|c|c|c|c|}
\hline & \multicolumn{2}{|c|}{ Level (Divergence) } & \multicolumn{2}{c|}{ Growth (Convergence) } \\
\hline & $1970-2001$ & $1960-2001$ & $1970-2001$ & $1960-2001$ \\
\hline INV & $\begin{array}{c}0.029 \\
(0.000)\end{array}$ & $\begin{array}{c}0.058 \\
(0.000)\end{array}$ & $\begin{array}{c}0.006 \\
(0.000)\end{array}$ & $\begin{array}{c}0.020 \\
(0.000)\end{array}$ \\
\hline BUD & $\begin{array}{c}0.094 \\
(0.000)\end{array}$ & $\begin{array}{c}0.119 \\
(0.000)\end{array}$ & $\begin{array}{c}0.032 \\
(0.000)\end{array}$ & $\begin{array}{c}0.040 \\
(0.000)\end{array}$ \\
\hline INF & $\begin{array}{c}0.004 \\
(0.000)\end{array}$ & $N S$ & $\begin{array}{c}-0.001 \\
(0.002)\end{array}$ & $N S$ \\
\hline POP & $N S$ & $\begin{array}{c}0.088 \\
(0.029)\end{array}$ & $\begin{array}{c}-0.036 \\
(0.006)\end{array}$ & $N S$ \\
\hline HC & $\begin{array}{c}0.202 \\
(0.000)\end{array}$ & $\begin{array}{l}0.165 \\
(0.000)\end{array}$ & $\begin{array}{c}0.045 \\
(0.000)\end{array}$ & $N S$ \\
\hline$\sigma$ & 0.494 & $\begin{array}{c}0.053 \\
(0.000)\end{array}$ & $\begin{array}{c}0.018 \\
(0.000)\end{array}$ & $N S$ \\
\hline
\end{tabular}

Note: P-values calculated from HACSE standard errors are in parentheses, $\sigma$ refers to regression standard error, $N S$ stands for not significant.

The results point out towards the importance of all main factors in determining the speed of convergence (divergence) of these output gaps. As expected physical capital and human capital play an important role in explaining whether two countries will likely have similar paths in their per capita GDP levels (and growth rates) and so does the fiscal discipline variable expressed by the budget deficit to GDP ratio. It is countries that have similar characteristics and pursue similar economic policies that are likely to have converging paths as opposed countries with dissimilar characteristics that may pursue different policies.

\section{Conclusions.}

In this paper, we examine a long memory framework of analysis allowing for the presence of structural breaks and the non reliance on a benchmark country to estimate the time series properties

\footnotetext{
${ }^{14}$ The reported results were obtained by using FELW estimator of $d$. However we obtained qualitatively similar results with other 3 estimators (FELWd, 2FELW, 2FELWd) of $d$.
} 
of output gaps for counties in the post world war two period and as such provide evidence for the convergence hypothesis. The focus in the paper is first the estimation of $d$, that is the parameter that determines the speed of convergence between different economies and second the examination of the effect on this parameter of certain important characteristics that are embedded in the majority of growth models, such as human capital, macroeconomic stability etc. The main finding of our paper is that for the per capita GDP gaps, the parameter $d$ takes values greater than 0.5 , for the per capita growth rates $d$ lies in the range $0 \leq d<0.5$. Lack of power does not enable us to obtain more precise estimates of $d$ and even though the long memory framework of analysis that we adopt is much richer than the simple $I(1) / I(0)$ alternative that produces a simple absolute divergence and rapid convergence dichotomy, the latter seems to be sufficient to capture the behavior of the gaps in per capita GDP levels and growth rates results. The former produce a pattern of divergence whereas the latter on of rapid convergence. Any evidence of mean reversion and long memory that we find is not strong enough. The speed of convergence (divergence) captured by the estimated parameter $d$, is explained by differences in physical and human capital differences as well as fiscal discipline characteristics of economic policies pursued by different countries. The more dissimilar countries are in terms of these factors the more likely they are to have divergent paths. 


\section{References}

[1] Abadir, Karim and Gabriel Talmain (2002) Aggregation, persistence and volatility in a macro model. Review of Economic Studies 69, 749-779.

[2] Abadir, Karim, Walter Distaso, and Liudas Giraitis (2007) Nonstationarity-extended local Whittle estimation. Journal of Econometrics 141: 1353-1384.

[3] Barro, Robert J. and Jong-Wha Lee (2001) International data on educational attainment: updates and implications. CID Working Paper 42.

[4] Becker, R., Walter Enders, and Stanley Hurn (2004) A general test for time dependence in parameters. Journal of Applied Econometrics 19, 899-906.

[5] Becker, R., Walter Enders, and Junsoo Lee (2006) A stationary test in the presence of an unknown number of smooth breaks. Journal of Time Series Analysis 27: 381-409.

[6] Bernard, Andrew B. and Steven N. Durlauf (1995) Convergence in international output. Journal of Applied Econometrics 10: 97-108.

[7] Bernard A.B and Steven N. Durlauf (1996) Interpreting tests of the convergence hypothesis. Journal of Econometrics 71: 161-173.

[8] Cheung, Ying-Wong and Antonio I.G. Pascual (2004) Testing for output convergence: a re-examination. Oxford Economic Papers 54: 45-63.

[9] Datta, Anusua (2003) Time series tests of convergence and transitional dynamics. Economics Letters 81: 233-240.

[10] Dufrénot, Gilles, Valérie Mignon, and Thao Naccache (2009) The slow convergence of per capita income between the developing countries: growth resistance and sometimes growth tragedy, Discussion Papers University of Nottingham, CREDIT.

[11] Durlauf, Steven N., Paul A. Johnson, and Jonathan R.W. Temple (2006) Growth econometrics. In P. Aghion, S.N. Durlauf (eds.), Handbook of Economic Growth, pp. 555-678. Amsterdam: North Holland.

[12] Haubrich, Joseph G. and Andrew W. Lo (2001) The sources and nature of long-term memory in aggregate output. Federal Reserve Bank of Cleveland Economic Review 2: 15-30. 
[13] Li, Qing and David H. Papell (1999) Convergence of international output: time series evidence for 16 OECD countries. International Review of Economics and Finance 8: 267-280.

[14] Ludlow, Jorge and Walter Enders (2000) Estimating non-linear ARMA models using Fourier coefficients. International Journal of Forecasting 16: 333-347.

[15] Kuensch, Hans R. (1987) Statistical aspects of self-similar processes. In Y. Prokhorov and V.V. Sazanov (eds.) Proceedings of the First World Congress of the Bernoulli Society, pp.6774. Utrecht: VNU Science Press.

[16] Maddison, Angus (2008) Statistics on world population, GDP and per capita GDP, 1-2006 AD. Available at http://www.ggdc.net/Maddison/Historical_Statistics/horizontalfile_02-2010.xls.

[17] Mello, Marcello (2010), Stochastic convergence across U.S. States. Macroeconomic Dynamics $1-24$.

[18] Michelacci, Claudio and Paolo Zaffaroni (2000) (Fractional) beta convergence. Journal of Monetary Economics 45: 129-153.

[19] Pesaran, M. Hashem (2007) A pair-wise approach for testing output and growth convergence. Journal of Econometrics 138: 312-355.

[20] Phillips, Peter C.B. and Donggyu Sul (2007a). Some empirics on economic growth under heterogeneous technology. Journal of Macroeconomics 29: 455-469.

[21] Phillips, Peter C.B. and Donggyu Sul (2007b) Transition modeling and econometric convergence tests. Econometrica 75: 1771-1855.

[22] Robinson, P.M. (1995) Gaussian semiparametric estimation of long range dependence. Annals of Statistics 23: 1630-1661.

[23] Shimotsu, Katsumi and Peter C.B. Phillips (2005) Exact local Whittle estimation of fractional integration. Annals of Statistics 33: 1890-1933.

[24] Shimotsu, Katsumi and Peter C.B. Phillips (2006) Local Whittle estimation of fractional integration and some of its variants. Journal of Econometrics 130: 209-233.

[25] Shimotsu, Katsumi (2008) Exact Local Whittle estimation of fractional integration with unknown mean and time trend. Econometric Theory 26: 501-540. 
[26] Velasco, Carlos (1999) Gaussian semiparametric estimation of non-stationary time series, Journal of Time Series Analysis 20: 87-127.

[27] Vikram, N. and A. Dhareshwar (1993) A new database on physical capital stock: sources, methodology and results. Rivista de Analisis Economico 8(1): 37-59.

[28] Vikram, Nehru, Eric Swanson, and Ashutosh Dubey, (1995) A new database on human capital stock in developing and industrial countries: sources, methodology and results. Journal of Development Economics 46: 379-401.

[29] WDI (2009) World Development Indicators on CD-ROM. The World Bank.

[30] WDI (2010) World Development Indicators on CD-ROM. The World Bank, 


\section{Tables and Figures}

Table 2: Fraction of Rejections for GDP per capita ( $\mathrm{T}=100,5 \%$ significance level)

\begin{tabular}{|c|c|c|c|c|c|c|c|c|c|c|c|c|c|c|c|c|c|c|c|}
\hline \multirow{2}{*}{\multicolumn{2}{|c|}{ Estimator }} & \multicolumn{3}{|c|}{ Test1 } & \multicolumn{3}{|c|}{ Test2a } & \multicolumn{3}{|c|}{ Test2b } & \multicolumn{3}{|c|}{ Test3 } & \multicolumn{3}{|c|}{ Test4 } & \multicolumn{3}{|c|}{ Abs. divergence } \\
\hline & & Min & Med & $\operatorname{Iax}$ & in & Med & $\mathrm{ax}$ & Iin & Med & $\mathrm{ax}$ & in & Med & $\mathrm{ax}$ & Iin & Med & $\mathrm{ax}$ & Min & Med & Max \\
\hline & LLW & 0.963 & 0.973 & 0.985 & 0.006 & 0.011 & 0.016 & 0.749 & 0.787 & 0.841 & 0.061 & 0.095 & 0.143 & 0.212 & 0.276 & 0.325 & 0.061 & 0.095 & 0.143 \\
\hline & FELWd & 0.969 & 0.973 & 0.977 & 006 & 0.007 & 008 & 0.762 & 0.795 & 0.836 & 0.067 & 0.085 & 0.102 & 0.212 & 0.276 & 0.327 & 0.067 & 085 & .102 \\
\hline & 2 FELW & 0.961 & 0.972 & 0.984 & 0.006 & 0.011 & 0.016 & 0.747 & 0.787 & 0.841 & 0.069 & 0.102 & 0.140 & 0.212 & 0.277 & 0.325 & 0.069 & .102 & 0.140 \\
\hline & 2FELWd & 0.968 & 0.972 & 0.977 & 0.006 & 0.007 & 0.008 & 0.758 & 0.793 & 0.834 & 0.084 & 0.105 & 0.125 & 0.213 & 0.277 & 0.327 & 0.084 & .105 & 0.125 \\
\hline & FELW & 0.963 & 0.979 & 0.986 & 0.000 & 0.006 & 0.010 & 0.739 & 0.786 & 828 & 0.068 & 0.102 & 0.153 & 0.216 & 0.235 & 0.261 & 0.068 & 102 & 0.153 \\
\hline & FELWd & 0.971 & 0.97 & 0.989 & 0.000 & 0.005 & 0.006 & 0.755 & 0.792 & 0.816 & 0.069 & 0.081 & 0.105 & 0.216 & 0.235 & 0.261 & 0.069 & 0.081 & 0.105 \\
\hline & 2 FELW & 0.962 & 0.978 & 0.986 & 0.000 & 0.006 & 0.010 & 0.739 & 0.786 & 0.829 & 0.075 & 0.109 & 0.155 & 0.217 & 0.236 & 0.264 & 0.075 & 0.109 & 0.155 \\
\hline & $2 \mathrm{FEL}$ & 0.971 & 0.977 & 0.989 & 0.000 & 0.004 & 0.006 & 0.754 & 91 & 0.816 & 0.090 & 0.111 & 0.141 & 0.217 & 0.236 & 64 & 0.090 & 111 & 0.14 \\
\hline & FELW & 0.927 & 0.954 & 0.972 & 0.011 & 0.020 & 0.026 & 0.718 & 0.731 & 0.762 & 0.129 & 0.159 & 0.200 & 0.090 & 0.118 & 0.148 & 0.129 & .159 & 0.200 \\
\hline & FELWd & 0.940 & 0.953 & 0.964 & 0.011 & 0.014 & 0.016 & 0.729 & 0.747 & 0.780 & 0.139 & 0.156 & 0.180 & 0.090 & 0.122 & 0.154 & 0.139 & 0.156 & 0.180 \\
\hline & 2 FELW & 0.908 & 0.938 & 0.962 & 0.015 & 0.026 & 0.032 & 0.692 & 0.708 & 0.749 & 0.140 & 0.175 & 0.218 & 0.090 & 0.119 & 0.149 & 0.140 & 0.175 & 0.218 \\
\hline & 2 FELWd & 0.923 & 0.940 & 0.950 & 0.015 & 0.018 & 0.020 & 0.704 & 0.724 & 0.756 & 0.150 & 0.176 & 0.205 & 0.090 & 0.122 & 0.154 & 0.150 & 0.176 & 0.205 \\
\hline & FELW & 961 & a & 0.988 & 4 & 0 & 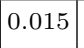 & 91 & & 3 & & & & 0.201 & & & 0.039 & 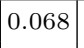 & 0.11 \\
\hline & FELWd & 0.969 & 0.977 & 0.985 & 0.002 & 0.004 & 0.006 & 0.799 & 0.852 & 0.900 & 0.039 & 0.059 & 0.084 & 0.201 & 0.324 & 0.443 & 0.039 & 0.059 & 0.084 \\
\hline & 2 FELW & 0.954 & 972 & 0.986 & 0.004 & 0.008 & 0.015 & 0.786 & 43 & 0.898 & 0.048 & 0.077 & 0.118 & 0.201 & 0.324 & 0.440 & 0.048 & 0.077 & 118 \\
\hline & 2FELWd & 0.963 & 0.974 & 0.984 & 0.002 & 0.004 & 0.006 & 0.796 & 0.847 & 0.896 & 0.053 & 0.080 & 0.108 & 0.201 & 0.324 & 0.443 & 0.053 & 0.080 & 0.108 \\
\hline & FELW & 0.959 & 0.970 & 0.979 & 0.009 & 0.013 & 0.019 & 0.730 & 0.759 & 0.814 & 0.077 & 0.114 & 0.148 & 0.197 & 0.248 & 0.283 & 0.077 & o.114 & 0.148 \\
\hline & FELWd & 0.961 & 0.968 & 0.979 & 0.007 & 0.009 & 0.011 & 0.744 & 0.765 & 0.808 & 0.079 & 0.095 & 0.108 & 0.197 & 0.248 & 0.282 & 0.079 & 0.095 & 0.108 \\
\hline & 2FELW & 0.960 & 0.970 & 0.980 & 0.008 & 0.012 & 0.017 & 0.732 & 0.760 & 0.815 & 0.091 & 0.125 & 0.147 & 0.198 & 0.249 & 0.283 & 0.091 & 0.125 & 0.147 \\
\hline & 2 FELW & 0.964 & 0.970 & 0.981 & 0.007 & 0.008 & 0.010 & 0.745 & 0.766 & 0.809 & 0.102 & 0.121 & 0.139 & 0.198 & 0.248 & 0.283 & 0.102 & 0.121 & 0.139 \\
\hline & FELW & \begin{tabular}{|l|}
0.959 \\
\end{tabular} & 67 & 0.977 & $\overline{009}$ & 0.013 & 0.016 & \begin{tabular}{|l|}
0.690 \\
\end{tabular} & 710 & 0.754 & 101 & 0.146 & 0.180 & 160 & 0.194 & 05 & 0.101 & 0.146 & 0.180 \\
\hline & FELWd & 0.944 & 0.958 & 0.978 & 0.007 & 0.013 & 0.019 & 0.700 & 0.719 & 0.742 & 0.122 & 0.142 & 0.159 & 0.160 & 0.194 & 0.206 & 0.122 & 0.142 & 0.159 \\
\hline & 2FELW & 0.956 & 0.965 & 0.974 & 0.008 & 0.013 & 0.015 & 0.686 & 0.708 & 0.753 & 0.120 & 0.161 & 0.177 & 0.160 & 0.194 & 0.205 & 0.120 & 0.161 & 0.177 \\
\hline & 2 FELWd & 0.941 & 0.955 & 0.981 & 0.007 & 0.013 & 0.019 & 0.693 & 0.714 & 0.736 & 0.150 & 0.159 & 0.185 & 0.160 & 0.194 & 0.206 & 0.150 & 0.159 & 0.185 \\
\hline & FELW & 0.963 & \begin{tabular}{|l|}
0.972 \\
\end{tabular} & 0.983 & 0.007 & 0.012 & 0.016 & 0.751 & 0.783 & 0.835 & 0.063 & 0.097 & 0.142 & 0.216 & 0.265 & 0.310 & 0.063 & 0.097 & 0.142 \\
\hline & FELWd & 0.967 & 71 & 0.977 & 0.006 & 0.008 & 0.009 & 0.764 & 0.789 & 0.826 & 0.072 & 0.089 & 0.103 & 0.217 & 0.265 & 0.312 & 0.072 & 089 & 103 \\
\hline & 2 FELW & 0.963 & 0.972 & 0.983 & 0.007 & 0.011 & 0.015 & 0.752 & 0.784 & 0.835 & 0.071 & 0.104 & 0.135 & 0.217 & 0.265 & 0.311 & 0.071 & 0.104 & 0.135 \\
\hline & $2 \mathrm{FELWd}$ & .967 & 0.972 & 0.977 & 0.006 & 0.007 & {$[0.008$} & $0.763 \mid$ & 0.788 & 0.826 & 0.089 & 0.107 & $0.121]$ & 0.218 & 0.266 & 0.312 & 0.089 & 0.107 & .121 \\
\hline
\end{tabular}

Note: Abs. divergence: Absolute divergence, 2FELW:2-Stage Feasible Exact Local Whittle estimator, 2FELWd: 2-Stage

Feasible Exact Local Whittle estimator with detrending, ALL: All countries, MEA: Middle-East and Asian countries,

EUR: European countries, AAP:Asian and Pacific countries, SSA: Sub-Saharan countries, WHE: Western-hemisphere countries, DEV: Developing countries. 
Table 3: Fraction of Rejections for GDP per capita ( $\mathrm{T}=200,5 \%$ significance level)

\begin{tabular}{|c|c|c|c|c|c|c|c|c|c|c|c|c|c|c|c|c|c|c|c|}
\hline \multirow{2}{*}{\multicolumn{2}{|c|}{ Estimator }} & \multicolumn{3}{|c|}{ Test1 } & \multicolumn{3}{|c|}{ Test2a } & \multicolumn{3}{|c|}{ Test2b } & \multicolumn{3}{|c|}{ Test3 } & \multicolumn{3}{|c|}{ Test4 } & \multicolumn{3}{|c|}{ Abs. divergence } \\
\hline & & Min & Med & $\operatorname{Iax}$ & in & Med & $a x$ & Min & Med & Max & Min & Med & Max & Min & Med & Max & Min & Med & Max \\
\hline & FELW & 0.969 & 0.977 & 0.987 & 0.007 & 0.012 & 0.018 & 0.770 & 0.807 & 0.858 & 0.068 & 0.103 & 0.152 & 0.243 & 0.309 & 0.361 & 0.068 & 0.103 & 0.152 \\
\hline & FELWd & 0.973 & 0.976 & 0.980 & 0.009 & 0.010 & 0.012 & 0.786 & 0.817 & 0.854 & 0.097 & 0.123 & 0.147 & 0.243 & 0.309 & 0.363 & 0.097 & 0.123 & 0.147 \\
\hline & 2FELW & 0.967 & 0.977 & 0.986 & 0.007 & 0.012 & 0.018 & 0.773 & 0.812 & 0.863 & 0.076 & 0.110 & 0.149 & 0.243 & 0.310 & 0.362 & 0.076 & 0.110 & 0.149 \\
\hline & 2FELWd & 0.973 & 0.976 & 0.980 & 0.008 & 0.010 & 0.011 & 0.790 & 0.820 & 0.857 & 0.097 & 0.121 & 0.144 & 0.244 & 0.310 & 0.363 & 0.097 & 0.121 & 0.144 \\
\hline & FELW & 0.970 & 0.983 & 0.989 & 0.000 & 0.007 & 0.013 & 0.762 & 0.810 & 0.852 & 0.074 & 0.109 & 0.158 & 0.249 & 0.269 & 0.301 & 0.074 & 0.109 & 0.158 \\
\hline & FELWd & 0.976 & 0.981 & 0.993 & 0.000 & 0.007 & 0.009 & 0.774 & 0.811 & 0.838 & 0.105 & 0.126 & 0.156 & 0.247 & 0.267 & 0.301 & 0.105 & 0.126 & 0.156 \\
\hline & 2FELW & 0.969 & 0.982 & 0.989 & 0.000 & 0.008 & 0.014 & 0.767 & 0.814 & 0.857 & 0.080 & 0.115 & 0.161 & 0.250 & 0.270 & 0.301 & 0.080 & 0.115 & 0.161 \\
\hline & 2FELWd & 0.976 & 0.981 & 0.993 & 0.000 & 0.006 & 0.008 & 0.782 & 0.816 & 0.844 & 0.104 & 0.128 & 0.158 & 0.247 & 0.267 & 0.301 & 0.104 & 0.128 & 0.158 \\
\hline & FELW & 0.937 & 0.960 & 0.977 & 0.012 & 0.022 & 0.029 & 0.739 & 0.753 & 0.781 & 0.138 & 0.167 & 0.203 & 0.119 & 0.148 & 0.176 & 0.138 & $0.167 \mid$ & 0.203 \\
\hline & FELWd & 0.948 & 0.958 & 0.969 & 0.013 & 0.017 & 0.019 & 0.752 & 0.769 & 0.798 & 0.158 & 0.177 & 0.200 & 0.119 & 0.152 & 0.184 & 0.158 & 0.177 & 0.200 \\
\hline & 2 FELW & 0.920 & 0.948 & 0.970 & 0.016 & 0.028 & 0.034 & 0.720 & 0.738 & 0.776 & 0.147 & 0.183 & 0.221 & 0.119 & 0.148 & 0.177 & 0.147 & 0.183 & 0.221 \\
\hline & 2 FELWd & 0.937 & 0.947 & 0.956 & 0.020 & 0.022 & 0.026 & 0.732 & 0.751 & 0.779 & 0.168 & 0.193 & 0.219 & 0.119 & 0.152 & 0.184 & 0.168 & 0.193 & 0.219 \\
\hline & FELW & 0.965 & 0.979 & 0.989 & 0.005 & 0.009 & 0.017 & 0.809 & 0.862 & 0.913 & 0.042 & 0.071 & 0.121 & 0.254 & 0.368 & 0.483 & 0.042 & 0.071 & 0.121 \\
\hline & FELWd & 0.978 & 0.984 & 0.988 & 0.004 & 0.007 & 0.009 & 0.826 & 0.871 & 0.914 & 0.054 & 0.083 & 0.118 & 0.255 & 0.369 & 0.487 & 0.054 & 0.083 & 0.118 \\
\hline & 2FELW & 0.960 & 0.976 & 0.988 & 0.005 & 0.010 & 0.017 & 0.812 & 0.863 & 0.913 & 0.051 & 0.082 & 0.122 & 0.255 & 0.368 & 0.484 & 0.051 & 0.082 & 0.122 \\
\hline & 2FELWd & 0.973 & 0.981 & 0.987 & 0.004 & 0.007 & 0.009 & 0.830 & 0.871 & 0.913 & 0.058 & 0.086 & 0.119 & 0.256 & 0.369 & 0.487 & 0.058 & 0.086 & 0.119 \\
\hline & FELW & 0.966 & 0.975 & 0.982 & 0.010 & 0.015 & 0.021 & 0.755 & 0.780 & 0.832 & 0.086 & 0.128 & 0.159 & 0.224 & 0.278 & 0.316 & 0.086 & 0.128 & 0.159 \\
\hline & FELWd & 0.965 & 0.971 & 0.979 & 0.008 & 0.013 & 0.016 & 0.768 & 0.789 & 0.828 & 0.118 & 0.144 & 0.165 & 0.225 & 0.278 & 0.316 & 0.118 & 0.144 & 0.165 \\
\hline & 2 FELW & 0.967 & 0.976 & 0.983 & 0.009 & 0.014 & 0.020 & 0.761 & 0.785 & 0.837 & 0.101 & 0.135 & 0.158 & 0.226 & 0.279 & 0.317 & 0.101 & 0.135 & 0.158 \\
\hline & 2FELWd & 0.968 & 0.973 & 0.981 & 0.007 & 0.011 & 0.013 & 0.777 & 0.798 & 0.834 & 0.118 & 0.139 & 0.159 & 0.226 & 0.279 & 0.317 & 0.118 & 0.139 & 0.159 \\
\hline & FELW & 0.967 & 0.973 & 0.981 & 0.011 & 0.016 & 0.019 & 0.712 & 0.729 & 0.778 & 0.111 & 0.157 & 0.190 & 0.187 & 0.218 & 0.232 & 0.111 & 0.157 & 0.190 \\
\hline & FELWd & 0.948 & 0.961 & 0.979 & 0.007 & 0.016 & 0.024 & 0.730 & 0.747 & 0.770 & 0.162 & 0.179 & 0.203 & 0.187 & 0.219 & 0.234 & 0.162 & 0.179 & 0.203 \\
\hline & 2 FELW & 0.967 & 0.972 & 0.980 & 0.010 & 0.015 & 0.018 & 0.718 & 0.735 & 0.784 & 0.128 & 0.171 & 0.187 & 0.187 & 0.218 & 0.232 & 0.128 & 0.171 & 0.187 \\
\hline & 2FELWd & 0.946 & 0.960 & 0.982 & 0.007 & 0.016 & 0.024 & 0.730 & 0.749 & 0.771 & 0.166 & 0.176 & 0.203 & 0.187 & 0.219 & 0.234 & 0.166 & 0.176 & 0.203 \\
\hline & FELW & 0.969 & 0.976 & 0.986 & 0.008 & 0.013 & 0.018 & 0.772 & 0.802 & 0.852 & 0.070 & 0.106 & 0.150 & 0.247 & 0.297 & 0.346 & 0.070 & 0.106 & 0.150 \\
\hline & FELWd & 0.971 & 0.975 & 0.980 & 0.008 & 0.010 & 0.013 & 0.788 & 0.811 & 0.845 & 0.103 & 0.127 & 0.146 & 0.248 & 0.296 & 0.347 & 0.103 & 0.127 & 0.146 \\
\hline & 2FELW & 0.969 & 0.977 & 0.986 & 0.007 & 0.012 & 0.017 & 0.778 & 0.807 & 0.858 & 0.079 & 0.113 & 0.144 & 0.248 & 0.298 & 0.347 & 0.079 & 0.113 & 0.144 \\
\hline & 2FELWd & 0.971 & 0.975 & 0.980 & 0.008 & 0.010 & 0.012 & 0.795 & 0.817 & 0.850 & 0.101 & 0.122 & 0.139 & 0.248 & 0.297 & 0.347 & 0.101 & 0.122 & $0.13 s$ \\
\hline
\end{tabular}

Note: Abs. divergence: Absolute divergence, 2FELW:2-Stage Feasible Exact Local Whittle estimator, 2FELWd: 2-Stage

Feasible Exact Local Whittle estimator with detrending, ALL: All countries, MEA: Middle-East and Asian countries,

EUR: European countries, AAP:Asian and Pacific countries, SSA: Sub-Saharan countries, WHE: Western-hemisphere countries, DEV: Developing countries. 
Table 4: Fraction of Rejections for GDP growth ( $\mathrm{T}=100,5 \%$ significance level)

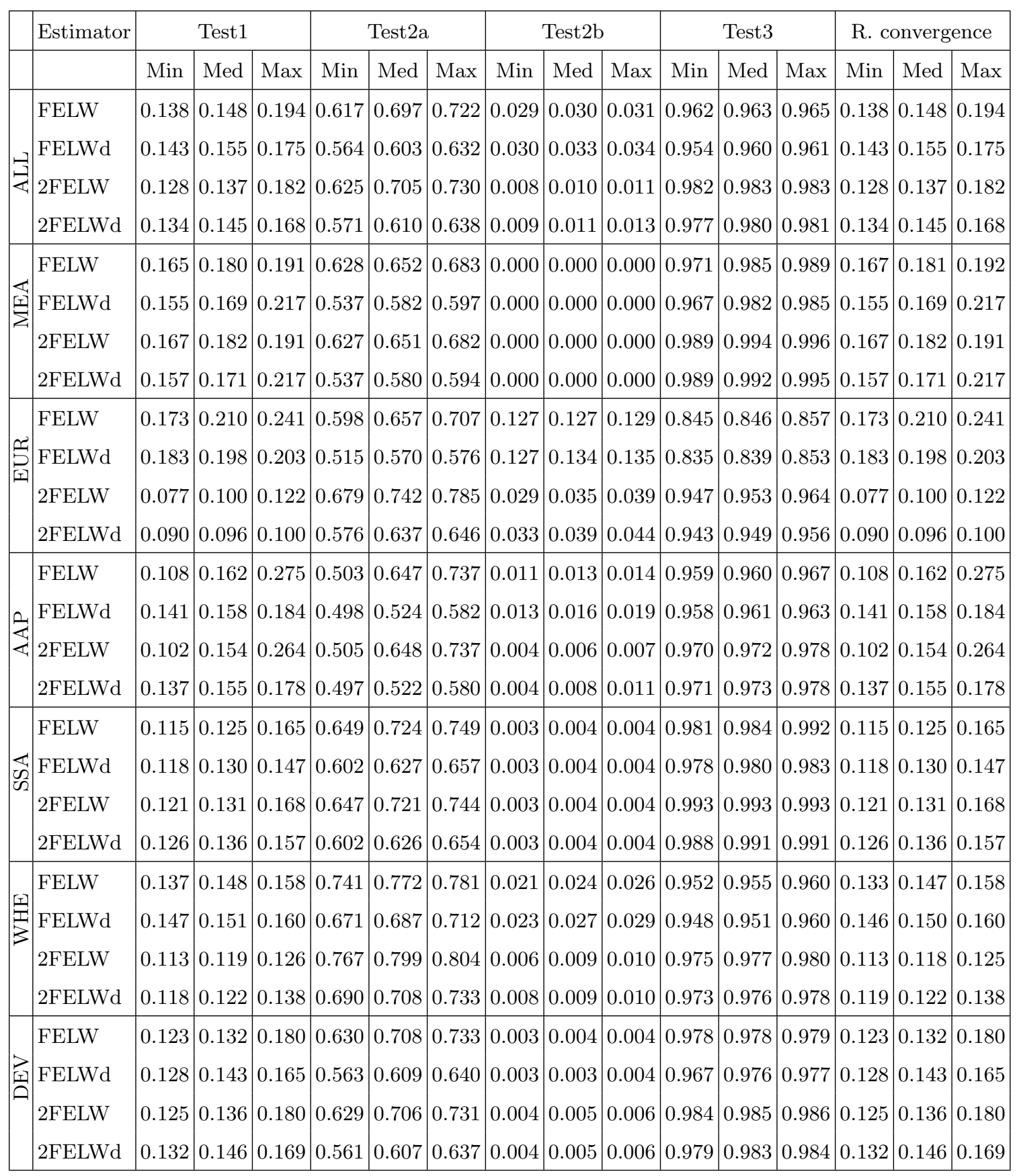

Note: R. convergence: Rapid convergence, 2FELW:2-Stage Feasible Exact Local Whittle estimator, 2FELWd: 2-Stage

Feasible Exact Local Whittle estimator with detrending, ALL: All countries, MEA: Middle-East and Asian countries, EUR: European countries, AAP:Asian and Pacific countries, SSA: Sub-Saharan countries, WHE: Western-hemisphere countries, DEV: Developing countries. 
Table 5: Fraction of Rejections for GDP growth ( $\mathrm{T}=200,5 \%$ significance level)

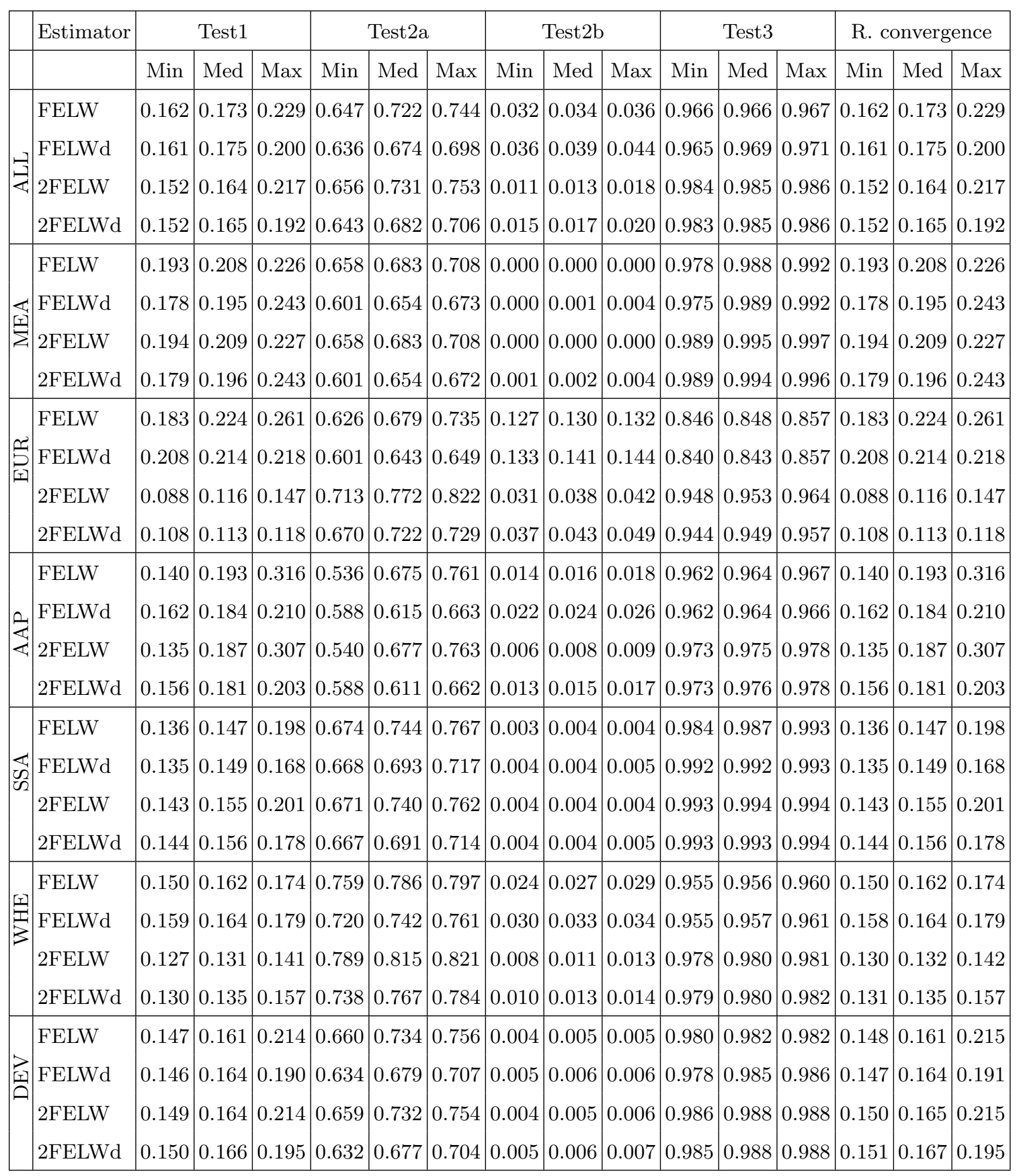

Note: R. convergence: Rapid convergence, 2FELW:2-Stage Feasible Exact Local Whittle estimator, 2FELWd: 2-Stage

Feasible Exact Local Whittle estimator with detrending, ALL: All countries, MEA: Middle-East and Asian countries, EUR: European countries, AAP:Asian and Pacific countries, SSA: Sub-Saharan countries, WHE: Western-hemisphere countries, DEV: Developing countries. 
Figure 1: Pesaran Statistics (a) $D_{t}^{2}=\frac{2}{N(N-1)} \sum_{i=1}^{N-1} \sum_{j=i+1}^{N}\left(y_{i t}-y_{j t}\right)^{2}$ and

(b) $M D_{t}=\frac{2}{N(N-1)} \sum_{i=1}^{N-1} \sum_{j=i+1}^{N}\left|y_{i t}-y_{j t}\right|$ for GDP per capita of different country groups.

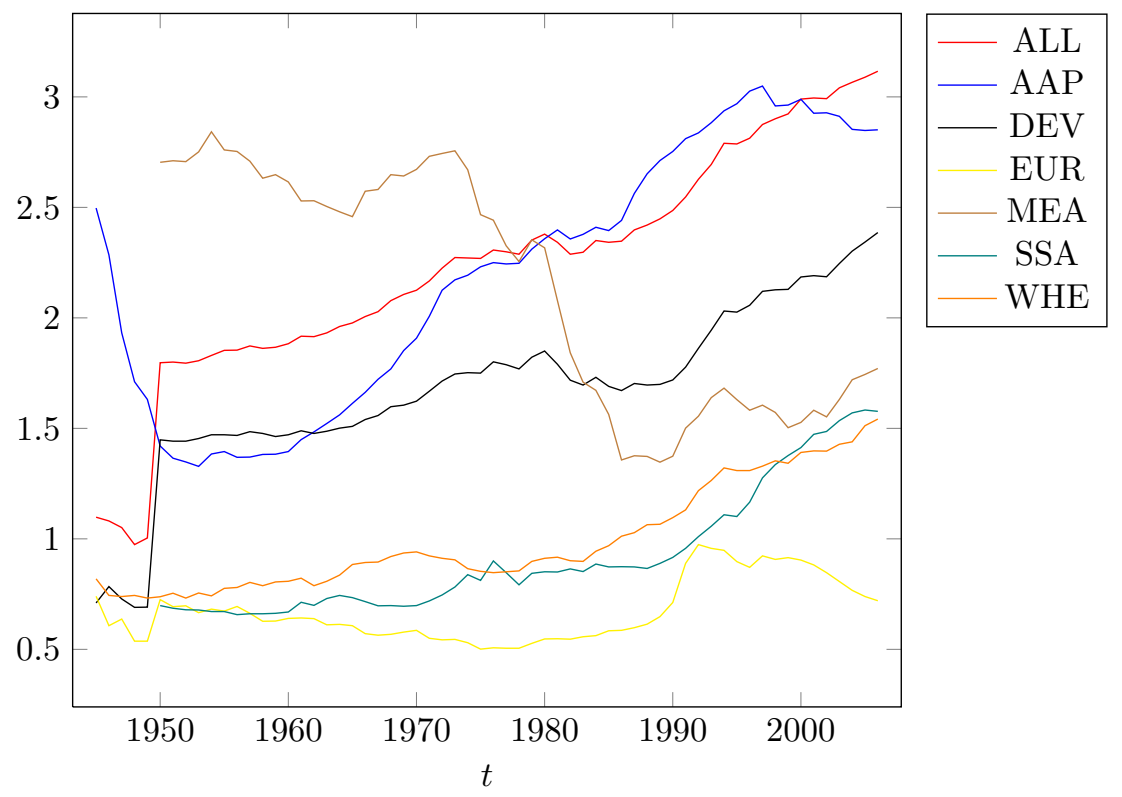

(a)

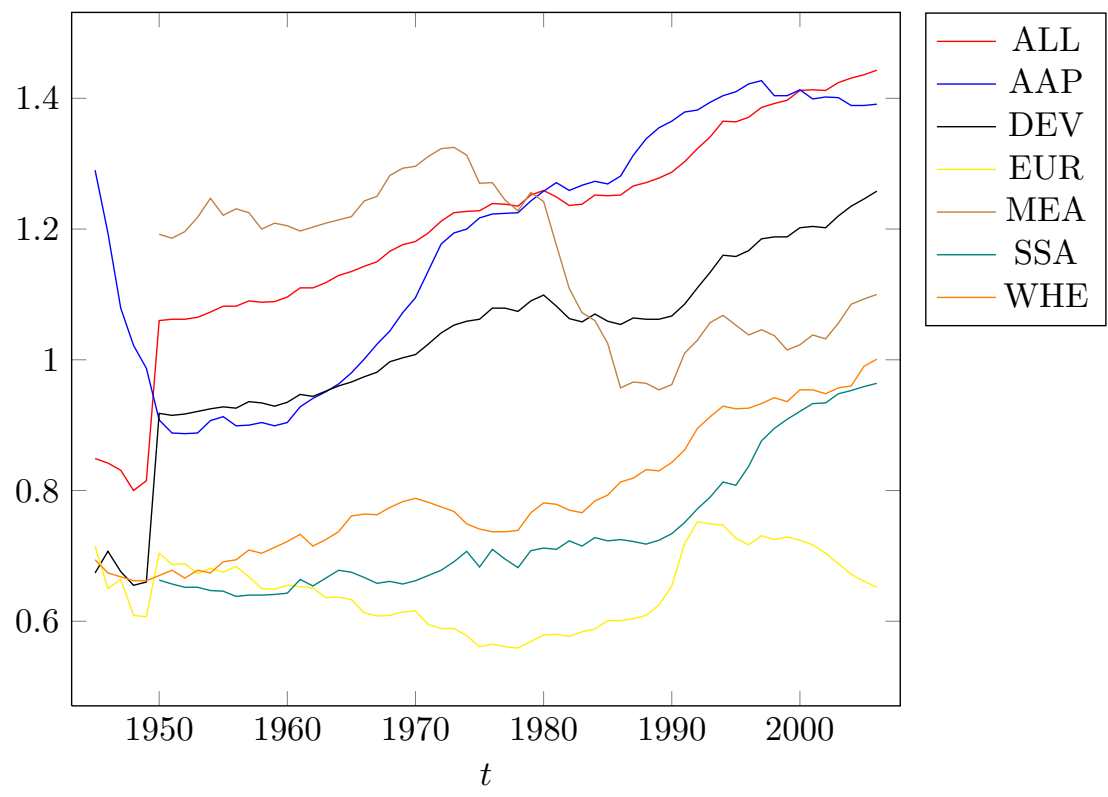

(b)

Note: ALL: All Countries, AAP: Asian and Pacific Countries, DEV: Developing Countries, EUR: European Countries, MEA: Middle-East and Central Asia Countries, SSA: Sub-Saharan African Countries, WHE: Western Hemisphere Countries. 
Figure 2: Pesaran Statistics (a) $D_{t}^{2}=\frac{2}{N(N-1)} \sum_{i=1}^{N-1} \sum_{j=i+1}^{N}\left(y_{i t}-y_{j t}\right)^{2}$ and

(b) $M D_{t}=\frac{2}{N(N-1)} \sum_{i=1}^{N-1} \sum_{j=i+1}^{N}\left|y_{i t}-y_{j t}\right|$ for GDP growth rate of different country groups.

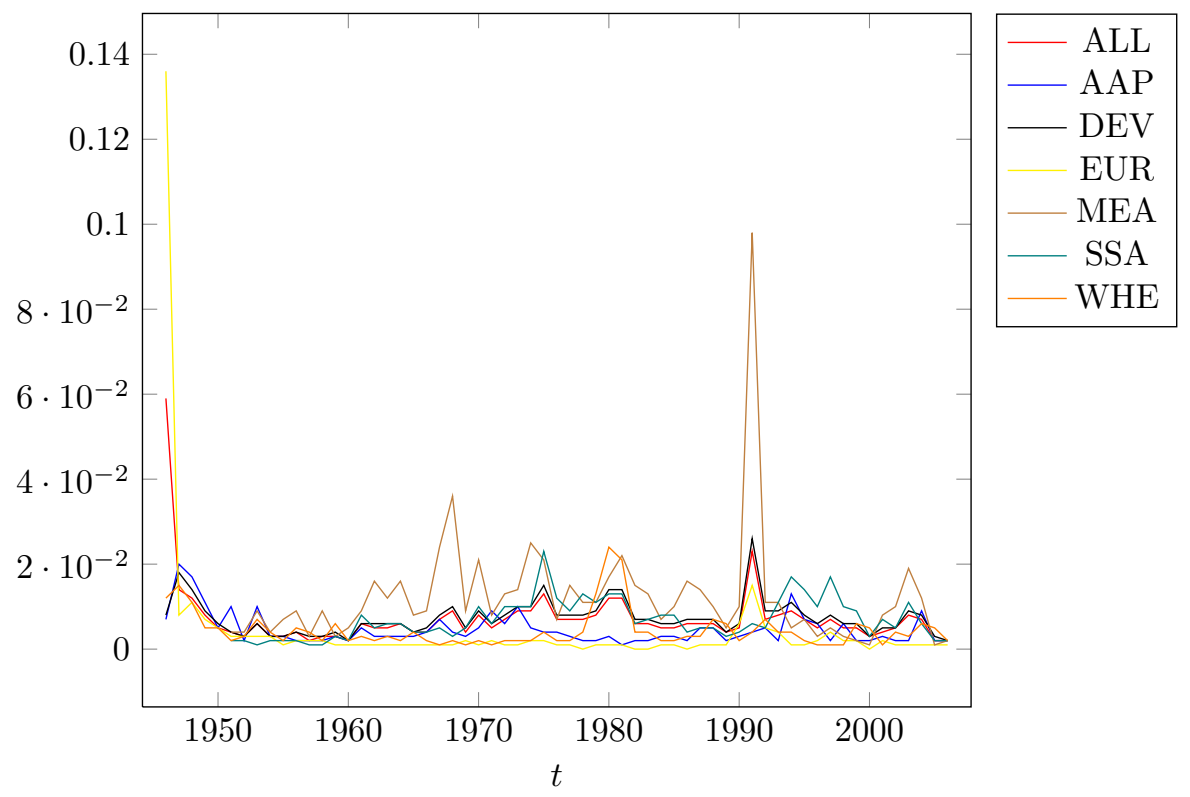

(a)

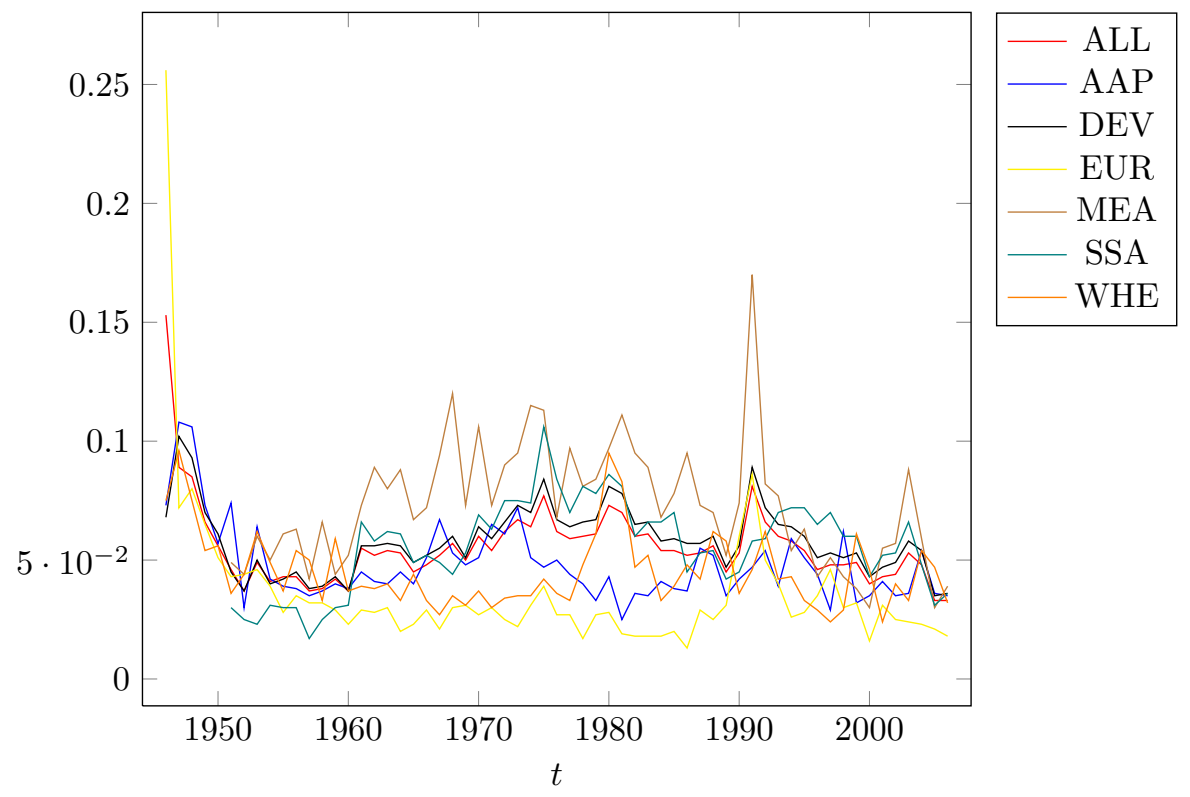

(b)

Note: ALL: All Countries, AAP: Asian and Pacific Countries, DEV: Developing Countries, EUR: European Countries, MEA: Middle-East and Central Asia Countries, SSA: Sub-Saharan African Countries, WHE: Western Hemisphere Countries. 


\section{Appendix}

Table A-1: Critical values of Test1-4, for $\mathrm{T}=100,200$, and 500.

(a) At $5 \%$ level of significance.

\begin{tabular}{|c|c|c|c|c|c|c|c|c|c|c|c|c|c|c|c|}
\hline & \multicolumn{3}{|c|}{ Test 1} & \multicolumn{3}{|c|}{ Test $2 \mathrm{a}$} & \multicolumn{3}{|c|}{ Test $2 \mathrm{~b}$} & \multicolumn{3}{|c|}{ Test 3} & \multicolumn{3}{|c|}{ Test 4} \\
\hline $\mathrm{CV}$ & & $95 \%$ & & & $05 \%$ & & & $95 \%$ & & & $05 \%$ & & & $95 \%$ & \\
\hline $\mathrm{T}$ & 100 & 200 & 500 & 100 & 200 & 500 & 100 & 200 & 500 & 100 & 200 & 500 & 100 & 200 & 500 \\
\hline EW & 2.007 & 1.857 & 1.732 & -2.491 & -2.255 & -2.020 & 2.013 & 1.910 & 1.839 & -2.417 & -2.199 & -1.959 & 1.616 & 1.525 & 1.502 \\
\hline ELW & 2.198 & 1.989 & 1.809 & -2.365 & -2.155 & -2.000 & 2.180 & 1.976 & 1.798 & -2.365 & -2.155 & -2.000 & 2.180 & 1.976 & 1.798 \\
\hline FELW & 2.207 & 1.990 & 1.812 & -2.216 & -2.076 & -1.930 & 2.254 & 2.071 & 2.084 & -2.253 & -2.153 & -2.000 & 2.180 & 1.974 & 1.798 \\
\hline FELWd & 1.945 & 1.765 & 1.624 & -3.079 & -2.668 & -2.355 & 2.149 & 1.939 & 1.938 & -2.647 & -2.235 & -2.042 & 2.175 & 1.975 & 1.795 \\
\hline 2FELW & 2.206 & 1.990 & 1.812 & -2.216 & -2.076 & -1.930 & 2.253 & 2.018 & 1.795 & -2.312 & -2.153 & -2.000 & 2.180 & 1.974 & 1.798 \\
\hline 2FELWd & 1.944 & 1.765 & 1.624 & -3.079 & -2.668 & -2.354 & 2.153 & 1.878 & 1.670 & -2.534 & $=-2.235$ & -2.042 & 2.175 & 1.975 & 1.795 \\
\hline
\end{tabular}

(b) At $10 \%$ level of significance.

\begin{tabular}{|c|c|c|c|c|c|c|c|c|c|c|c|c|c|c|c|}
\hline & \multicolumn{3}{|c|}{ Test 1} & \multicolumn{3}{|c|}{ Test $2 \mathrm{a}$} & \multicolumn{3}{|c|}{ Test $2 \mathrm{~b}$} & \multicolumn{3}{|c|}{ Test 3} & \multicolumn{3}{|c|}{ Test 4} \\
\hline $\mathrm{CV}$ & & $90 \%$ & & & $10 \%$ & & & $90 \%$ & & & $10 \%$ & & & $90 \%$ & \\
\hline $\mathrm{T}$ & 100 & 200 & 500 & 100 & 200 & 500 & 100 & 200 & 500 & 100 & 200 & 500 & 100 & 200 & 500 \\
\hline EW & 1.548 & 1.428 & 1.344 & -1.930 & 1.554 & -1.722 & 1.480 & -1.551 & 1.447 & -1.883 & -1.702 & -1.517 & 1.192 & 1.129 & 1.130 \\
\hline ELW & 1.743 & 1.558 & 1.416 & -1.778 & 1.728 & -1.629 & 1.546 & -1.538 & 1.413 & -1.778 & -1.629 & -1.538 & 1.728 & 1.546 & 1.413 \\
\hline FELW & 1.749 & 1.563 & 1.418 & -1.656 & 1.799 & -1.543 & 1.755 & -1.469 & 1.723 & -1.765 & -1.632 & -1.538 & 1.725 & 1.546 & 1.413 \\
\hline FELWd & 1.437 & 1.305 & 1.200 & -2.413 & 1.616 & -2.103 & 1.570 & -1.854 & 1.557 & -1.880 & -1.705 & -1.579 & 1.721 & 1.545 & 1.412 \\
\hline 2FELW & 1.748 & 1.563 & 1.418 & -1.658 & 1.768 & -1.543 & 1.567 & -1.469 & 1.432 & -1.763 & -1.632 & -1.538 & 1.725 & 1.546 & 1.413 \\
\hline $2 \mathrm{FELWd}$ & 1.435 & 1.305 & 1.200 & -2.413 & 1.590 & -2.103 & 1.391 & -1.854 & 1.266 & -1.881 & -1.705 & -1.579 & 1.721 & 1.545 & 1.412 \\
\hline
\end{tabular}

Note: EW: Exact Whittle, ELW: Exact local Whittle, FELW: Feasible Exact local Whittle, 2FELW:2-Stage Feasible Exact Local Whittle estimator, 2FELWd: 2-Stage Feasible Exact Local Whittle estimator with detrending. Simulations are carried out by assuming $v=T^{0.6}$. 
Table A-2: Country groups definitions.

\begin{tabular}{|c|c|}
\hline $\begin{array}{l}\text { Middle-East } \\
\text { and } \\
\text { Central Asia }\end{array}$ & $\begin{array}{l}\text { Algeria, Bahrain, Iran, Iraq, Kuwait, Libya, Oman, Qatar, Saudi Arabia, Sudan, } \\
\text { United Arab Emirates, Yemen, Afghanistan, Djibouti, Egypt, Jordan, Lebanon, Mau- } \\
\text { ritania, Morocco, Pakistan, Syria, Tunisia, West Bank and Gaza, Somalia. }\end{array}$ \\
\hline Europe & $\begin{array}{l}\text { Albania, Austria, Belgium, Bulgaria, Czech Republic, Denmark, Finland, France, } \\
\text { Germany, Greece, Hungary, Ireland, Italy, Israel, Netherlands, Norway, Portugal, } \\
\text { Poland,Romania, Spain, Sweden, Switzerland, Turkey, United Kingdom, Yugoslavia. }\end{array}$ \\
\hline Asia and & $\begin{array}{l}\text { Australia, Bangladesh, Burma, Cambodia, China, Hong Kong, New Zealand, India, } \\
\text { Indonesia, Japan, Laos, Malaysia, Mongolia, Nepal, North Korea, Philippines, Singa- } \\
\text { pore, South Korea, Sri Lanka, Taiwan, Thailand, Vietnam. }\end{array}$ \\
\hline Sub-Saharan & $\begin{array}{l}\text { Angola, Benin, Botswana, Burkina Faso, Burundi, Côte d'Ivoire, Cameroon, Cape } \\
\text { Verde, Central African Republic, Chad, Comoro Islands, Democratic Republic of } \\
\text { Congo (formerly Zaire), Equatorial Guinea, Eritrea and Ethiopia, Gabon, Gambia, } \\
\text { Ghana, Guinea, Guinea Bissau, Kenya, Lesotho, Liberia, Madagascar, Malawi, Mali, } \\
\text { Mauritius, Mozambique, Namibia, Niger, Nigeria, Rwanda, São Tomé and Principe, } \\
\text { Republic of Congo, Senegal, Seychelles, Sierra Leone, South Africa, Swaziland, Tan- } \\
\text { zania, Togo, Uganda, Zambia, Zimbabwe. }\end{array}$ \\
\hline $\begin{array}{l}\text { Western } \\
\text { Hemisphere }\end{array}$ & $\begin{array}{l}\text { Argentina, Bolivia, Brazil, Canada, Chile, Colombia, Costa Rica, Cuba, Domini- } \\
\text { can Republic, Ecuador, El Salvador, Guatemala, Haiti, Honduras, Jamaica, Mex- } \\
\text { ico, Nicaragua, Panama, Paraguay, Peru, Puerto Rico, Trinidad and Tobago, United } \\
\text { States, Uruguay, Venezuela. }\end{array}$ \\
\hline
\end{tabular}

Table A-3: List of countries used in determinants of convergence

\begin{tabular}{|l|l|}
\hline \multirow{1}{*}{$1960-2001$} & $\begin{array}{l}\text { Australia, Austria, Belgium, Bolivia, Botswana, Brazil, Canada, Chile, China, Congo, } \\
\text { Costa Rica, Denmark, Dominican Republic, Ecuador, Egypt, El Salvador, Finland, } \\
\text { France, Ghana, Greece, Guatemala, Honduras, Hungary, India, Iran, Ireland, Israel, } \\
\text { Italy, Japan, Kenya, Lesotho, Malaysia, Mali, Mexico, Netherlands, New Zealand, } \\
\text { Norway, Pakistan, Paraguay, Peru, Philippines, Portugal, Rwanda, Senegal, Singa- } \\
\text { pore, South Africa, South Korea, Spain, Sri Lanka, Swaziland, Sweden, Switzerland, } \\
\text { Thailand, Trinidad and Tobago, Tunisia, Turkey, United Kingdom, United States, } \\
\text { Uruguay, Uruguay, Venezuela, Zambia, Zimbabwe. }\end{array}$ \\
\hline $\begin{array}{l}\text { Canada, Chile, Congo, Costa Rica, Dominican Republic, Egypt, El Salvador, Fin- } \\
\text { land, Greece, Guatemala, Honduras, Hungary, India, Israel, Italy, Japan, Malaysia, } \\
\text { Mexico, Pakistan, Paraguay, Peru, Philippines, South Africa, South Korea, Swe- } \\
\text { den, Switzerland, Thailand, Trinidad and Tobago, United Kingdom, United States, } \\
\text { Uruguay, Venezuela, Zimbabwe. }\end{array}$ \\
\hline
\end{tabular}

